\title{
The Controlled Synthesis of Carbon Tubes and Rods by Template-Assisted Twin Polymerization
}

\author{
Falko Böttger-Hiller, ${ }^{1}$ Patrick Kempe, ${ }^{1}$ Gisela Baumann, ${ }^{2}$ \\ Michael Hietschold, ${ }^{2}$ Philipp Schäfer, ${ }^{2}$ Dietrich R. T. Zahn, ${ }^{2}$ Albrecht Petzold, ${ }^{3}$ \\ Thomas Thurn-Albrecht, ${ }^{3}$ and Stefan Spange ${ }^{1}$ \\ ${ }^{1}$ Department of Polymer Chemistry, Technische Universität Chemnitz, Straße der Nationen 62, 09111 Chemnitz, Germany \\ ${ }^{2}$ Institute of Physics, Technische Universität Chemnitz, Reichenhainer Straße 70, 09107 Chemnitz, Germany \\ ${ }^{3}$ Department of Chemistry and Physics, Martin Luther University Halle-Wittenberg, Von-Danckelmann-Platz 3, \\ 06120 Halle, Germany \\ Correspondence should be addressed to Falko Böttger-Hiller; falko.boettger-hiller@mb.tu-chemnitz.de
}

Received 8 May 2013; Accepted 5 October 2013

Academic Editor: Luigi Nicolais

Copyright (C) 2013 Falko Böttger-Hiller et al. This is an open access article distributed under the Creative Commons Attribution License, which permits unrestricted use, distribution, and reproduction in any medium, provided the original work is properly cited.

\begin{abstract}
The application of porous carbon is versatile. It is used for high-performance catalyst support, electrode material in batteries, and gas storage. In each of these application fields nanostructuring improves the material properties. Supercapacitors store a high energy density. Exactly adapted carbon structures increase the life of lithium batteries and protect catalysts with increasing reaction rate and selectivity. Most of porous carbon materials have a spherical shape. To the best of our knowledge, there is no procedure to synthesize nanostructured cylindrical porous carbon systematically. Here, template glass fibres and $\mathrm{SiO}_{2}$-tubes were modified with nanostructured $\mathrm{SiO}_{2} /$ phenolic resin and $\mathrm{SiO}_{2} /$ poly (furfuryl alcohol) layers by surface twin polymerization (TP) of $2,2^{\prime}$-spirobi[ $4 H$ 1,3,2-benzodioxasiline] and tetrafurfuryloxysilane. Afterwards the $\mathrm{SiO}_{2}$ /polymer layer on the template is thermally transformed into a defect-free nanostructured $\mathrm{SiO}_{2}$ /carbon layer. After completely removing the $\mathrm{SiO}_{2}$ components microporous carbon tubes or rods are finally achieved. The diameters of the carbon rods and the inner as well as the outer diameter of the carbon tubes are adjustable according to the shape and size of the template. Thus, a huge variety of microporous carbon materials can be easily produced by template-assisted TP.
\end{abstract}

\section{Introduction}

Application of porous hollow carbon material is versatile [1$3]$; it is used for high-performance catalyst support [4-6], electrode material in batteries [7,8], gas storage [9], and filters [10]. In each of these application fields nanostructuring improves the material properties. Supercapacitors store a high energy density. Exactly adapted carbon structures increase the life of lithium batteries and protect catalysts with increasing reaction rate and selectivity.

Most pathways to produce hollow carbon rely on hard templating and solvothermal treatment $[1,2]$. In literature many porous carbon bodies with different properties were described [2]. The most reported porous carbon bodies have a spherical shape [2]. Just a few publications describe the synthesis of hollow carbon vessels with wormlike structures, tubes, and hollow fibres [1, 11-15].

One requirement for producing porous carbon with pore size dimensions on the nanoscale down to $0.5 \mathrm{~nm}$ presuppose, the accessibility of nanostructured inorganic/organic hybrid materials which can be transformed to carbon after carbonizing the organic component and removing the noncarbon component. For this purpose nanostructured $\mathrm{SiO}_{2} /$ polymer hybrid materials have been established as suitable precursors for bulk carbon materials with large pore volume [16].

The production of nanostructured inorganic oxide/polymer hybrid materials is not easy to perform, because two different components must be brought together on the molecular level in such a way that no phase separation process takes place. One established way is to polymerize two different 
monomers simultaneously in one procedure by adjusting the reaction conditions $[17,18]$. A more elegant way is the use of monomers which contain two differently polymerizable groups in one molecule [19-21]. Each polymerizable functional group of such a heterobifunctional monomer polymerizes independently of the others and by another mechanism. Depending on the reaction conditions both processes can be done either simultaneously or consecutively. Mainly sol-gel processes are still used in inorganic component formation from hetero bifunctional monomer [17-20].

The twin polymerization (TP) is distinguished from the just mentioned methods [22-27] and was used in combination with spherical hard templates to synthesize size adjustable carbon hollow spheres with micro- or mesoporous shells [27]. TP requires the use of so-called twin monomer, an adequate inorganic/organic hybrid monomerwhich undergoes polymerization to two different polymers in one process. Both polymerization processes are associated with each other and are mechanistically coupled [16, 22-25]. After the activation of a twin monomer both units polymerize simultaneously and the occurring inorganic polymer determines the structure of the organic polymer and vice versa. Thus, a nanostructured hybrid material is obtained. The silicon containing twin monomers, 2,2' -spirobi[4H-1,3,2benzodioxasiline] (1) and tetrafurfuryloxysilane (2), yielded in nanostructured $\mathrm{SiO}_{2} /$ polymer hybrid materials. Starting from this material it is possible to obtain porous carbon by carbonizing the organic phase and removing the $\mathrm{SiO}_{2}$ phase by treatment with hydrofluoric acid (Figure 1).

In this report we present a novel route to fabricate cylindrical porous carbon compounds based on TP in combination with hard templates. Both twin monomers result in porous carbon after polymerization, carbonization, and treatment with aqueous hydrofluoric acid $[16,22]$.

According to Figure 1 dip-coating of a fibre template will lead to a hybrid layer on the surface after TP. Removing the $\mathrm{SiO}_{2}$ phase results in a porous carbon tube (Figure 1(c)). A tubular template will lead to a porous carbon tube (outer layer) and a porous carbon rod (inner layer) (Figure 1(d)).

\section{Experimental}

\subsection{Preparation}

\subsubsection{Monomer Synthesis}

(1) Synthesis of Monomer 1: 2,2'-Spirobi[4H-1,3,2-benzodioxasiline] [16]. $35.00 \mathrm{~g}$ salicyl alcohol $(0.28 \mathrm{~mol})$ was dissolved in $300 \mathrm{~mL}$ toluene at $85^{\circ} \mathrm{C}$ under dry argon atmosphere. $0.1 \mathrm{~mL}$ tetra- $n$-butylammonium fluoride ( $1 \mathrm{M}$ in THF) was added. Tetramethoxysilane $(21.46 \mathrm{~g}, 0.14 \mathrm{~mol})$ was dropped slowly into the hot solution. After $1 \mathrm{~h}$, methanol was removed under reduced pressure and the clear toluene solution was decanted from viscous byproducts. Colourless crystals were obtained after evaporating of the toluene and recrystallization using hexane. Yield was $80 \%$; m.p. $82-84^{\circ} \mathrm{C} ;{ }^{1} \mathrm{H}$ NMR (400 MHz, $\mathrm{CDCl}_{3}, 25^{\circ} \mathrm{C}$, TMS) $\delta=7.21-7.27$ (m, 2H), 6.97$7.05(\mathrm{~m}, 6 \mathrm{H}), 5.25-5.17 \mathrm{ppm}\left(2 \mathrm{~d},{ }^{2} \mathrm{~J}(\mathrm{H}, \mathrm{H})=14.2 \mathrm{~Hz}, 4 \mathrm{H}\right.$,
$\left.\mathrm{CH}_{2}\right) ;{ }^{13} \mathrm{C} \mathrm{NMR}\left(100 \mathrm{MHz}, \mathrm{CDCl}_{3}, 25^{\circ} \mathrm{C}, \mathrm{TMS}\right): \delta=152.4$, $129.1,125.7,125.2,122.3,119.3,66.3 \mathrm{ppm}\left(\mathrm{CH}_{2}\right) ;{ }^{29} \mathrm{Si}$ CP-MASNMR (79.49 MHz, $\left.25^{\circ} \mathrm{C}\right): \delta=-78.37 \mathrm{ppm}$ confirming a fourfold coordination; elemental analysis (\%) calcd/found for $\mathrm{C}_{14} \mathrm{H}_{12} \mathrm{O}_{4}$ Si: $\mathrm{C}(61.75 / 60.07), \mathrm{H}(4.44 / 4.29)$-deviation can occur due to possible decomposition (hydrolysis) caused by noninert measurement method; C-content confirms fourfold coordination.

(2) Synthesis of Monomer 2: Tetrafurfuryloxysilane [22]. $(90 \mathrm{~mL}, 0.4 \mathrm{~mol})$ and furfuryl alcohol $(141 \mathrm{~mL}, 1.6 \mathrm{~mol})$ were mixed, and 0.3 wt- $\%$ of $\mathrm{KOH}$ was added. The mixture was stirred for $3 \mathrm{~h}$ at $80^{\circ} \mathrm{C}$ and $65 \mathrm{mbar}$. Then the pressure was reduced over $1 \mathrm{~h}$ to 3 mbar and the by-products were distilled off. The product was obtained at $240{ }^{\circ} \mathrm{C}$ and 0.4 mbar. Light yellow crystals precipitated at $0^{\circ} \mathrm{C}$ and could be recrystallized from diethyl ether. Yield was 60\%, m.p. $39^{\circ} \mathrm{C},{ }^{1} \mathrm{H} \mathrm{NMR}\left(400 \mathrm{MHz}, \mathrm{CDCl}_{3}, 25^{\circ} \mathrm{C}\right) \delta=4.73 \mathrm{ppm}$ $(8 \mathrm{H}, \mathrm{s}), 6.32(4 \mathrm{H}, \mathrm{dd}), 6.25(4 \mathrm{H}, \mathrm{m}), 7.44(4 \mathrm{H}, \mathrm{dd}) ;{ }^{13} \mathrm{C}$ NMR (100 MHz, d $\mathrm{d}^{6}$-Acetone), $25^{\circ} \mathrm{C}: \delta=58.5,108.8,110.8$, $142.8,155.6 \mathrm{ppm}$; elemental analysis (\%) calcd/found for $\mathrm{C}_{20} \mathrm{H}_{20} \mathrm{O}_{8}$ Si: $\mathrm{C}(57.00 / 57.70), \mathrm{H}(4.90 / 4.80)$-deviation can occur due to possible decomposition (hydrolysis) caused by non-inert measurement method.

\subsubsection{Porous Carbon by Template-Free Synthesis (Reference Samples)}

(1) Porous Carbon from Acid Induced Twin Monomers. According to literature [16] $2 \mathrm{~g}$ of 1 was dissolved in $50 \mathrm{~mL}$ of toluene and given to a solution of $240 \mathrm{mg}$ methanesulfonic acid in $250 \mathrm{~mL}$ toluene. The mixture was stirred for $15 \mathrm{~h}$. The precipitate was filtered and washed with $100 \mathrm{~mL}$ dichloromethane. $1.8 \mathrm{~g}$ (yield: $80 \%$ ) of pink powder was obtained. When using $2 \mathrm{~g}$ of $\mathbf{2}$ in the same procedure an amount of $0.78 \mathrm{~g}$ (yield: $35 \%$ ) of a black solid results.

After polymerization a carbonization step (heat rate: $6.2 \mathrm{~K} \mathrm{~min}^{-1}, 800^{\circ} \mathrm{C}$ for $3 \mathrm{~h}$ ) under argon followed. $\mathrm{SiO}_{2}$ was removed by treating the samples with aqueous hydrofluoric acid (40\%) for 3 days.

(2) Porous Carbon from Thermally Induced Twin Monomers. The reference-hybrid derived from thermally induced TP of 1 was synthesized by heating $7 \mathrm{~g}$ of 1 up to $200^{\circ} \mathrm{C}$ under air on a heating table. After $1 \mathrm{~h}$ at this temperature $6.6 \mathrm{~g}$ (yield: $94 \%$ ) of a brownish, transparent $\mathrm{SiO}_{2}$ /polymer hybrid is obtained. For thermal TP of $2 \mathrm{a}$ mass of $6 \mathrm{~g}$ monomer was heated for $1 \mathrm{~h}$ in a preheated $\left(T=200^{\circ} \mathrm{C}\right)$ muffle furnace and $3.9 \mathrm{~g}$ (yield: $65 \%$ ) of brown hybrid material was obtained.

After polymerizing the monomers to $\mathrm{SiO}_{2} /$ polymer hybrid, a carbonization step (heat rate: $6.2 \mathrm{~K} \mathrm{~min}^{-1}, 800^{\circ} \mathrm{C}$ for $3 \mathrm{~h}$ ) under argon followed. $\mathrm{SiO}_{2}$ was removed by treating the samples with aqueous hydrofluoric acid.

2.1.3. Carbon by Template-Assisted Procedure. $1 \mathrm{~g}$ template was dipped into a solution of $1 \mathrm{~g}$ methanesulfonic acid in $20 \mathrm{~mL}^{-1}$ toluene for $10 \mathrm{~s}$ and afterwards for $10 \mathrm{~s}$ into a melt 


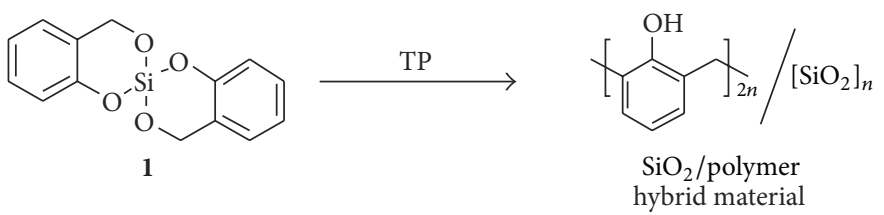

(a)

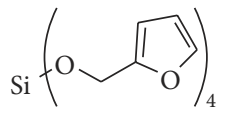

2

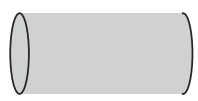

Template fibre

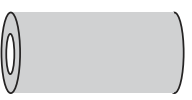

Template tube

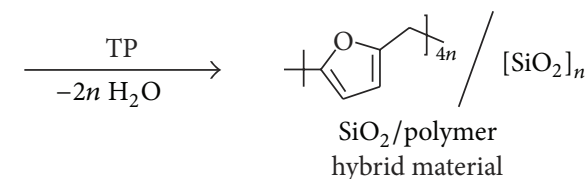

(b)

\section{(1) Twin monomer $\underset{\text { dip-coated }}{\stackrel{\text { Surface TP }}{\longrightarrow}}$}

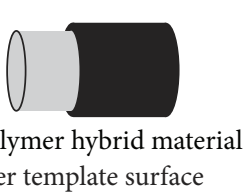

(c) (1) Twin monomer
$\underset{\text { dip-coated }}{ }$
(2) Surface TP

$\mathrm{SiO}_{2} /$ polymer hybrid material at inner and outer template surfaces

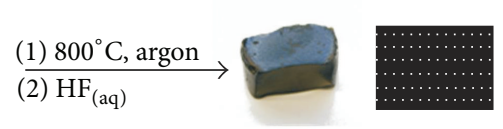

Mostly microscopic carbon $(d<2 \mathrm{~nm}, 72 \mathrm{vol}-\%)$

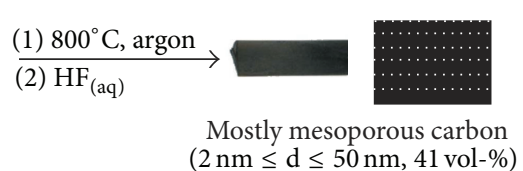

$(2 \mathrm{~nm} \leq \mathrm{d} \leq 50 \mathrm{~nm}, 41$ vol- $\%)$

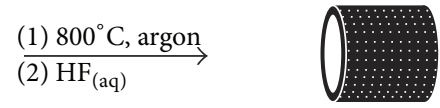

Porous carbon tube

$\mathrm{SiO}_{2} /$ polymer hybrid mater
at outer template surface

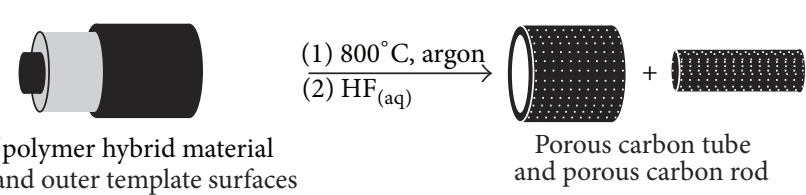

(d)

Figure 1: (a) Synthesis of mostly microporous $(d<2 \mathrm{~nm}, 72$ vol-\%) carbon by acid induced TP of 1; (b) synthesis of mostly mesoporous carbon ( $2 \mathrm{~nm} \leq d \leq 50 \mathrm{~nm}, 41 \mathrm{vol}-\%)$ by TP of 2 ; principle of template assisted TP on (c) template fibres and (d) at template tubes.

or solution of twin monomer. The coated template was dried in air over night at room temperature.

In a typical thermal induced TP synthesis $1 \mathrm{~g}$ template was dipped into $2 \mathrm{~g}$ of monomer melt $\left(T_{\text {tube }}=90^{\circ} \mathrm{C}, T_{\text {rod }}=50^{\circ} \mathrm{C}\right)$, heated to $200^{\circ} \mathrm{C}$, and held at this temperature for 15 minutes. After thermal polymerization a carbonization step (heat rate: $6.2 \mathrm{~K} \mathrm{~min}^{-1}, 800^{\circ} \mathrm{C}$ for $3 \mathrm{~h}$ ) under argon followed. $\mathrm{SiO}_{2}$ was removed by treating the samples with aqueous hydrofluoric acid.

2.2. Chemicals. Tetraethoxysilane (Acros, 98\%) and furfuryl alcohol (Acros, 99\%) were distilled and stored under argon. 2-Hydroxybenzyl alcohol (ABCR, 99\%), methanesulfonic acid (Alfa Aesar, 98+\%), tetra- $n$-butylammonium fluoride (1 M in THF), tetramethoxysilane (Fluka, 98\%), and aqueous hydrofluoric acid (Prolabo, 40\%) are commercially available and were used without further purification.

Glass fibres were provided by Cordus $\mathrm{GmbH}$ and ORMOCERs by Fraunhofer-Institut Würzburg. Glass capillaries from Lab Logistics Group $\mathrm{GmbH}$ were used. All substrates were used without purification.

2.3. Physicochemical Characterization. The carbon samples were imaged by a scanning electron microscope Philips SEM 515 and a NovaNanoSEM (FEI), the latter having Schottky field emission gun.
The pore texture was analyzed by measuring nitrogensorption-isotherms with a Sorptomatic 1990 (Fisons). The pore-size distribution plots of the carbon materials were calculated from nitrogen-sorption-isotherms by the method of Horvath and Kawazoe [26] according to DIN 66135.

To measure the length scale of the pore texture of the carbon materials made from 1 and 2, small angle Xray scattering (SAXS) measurements were used. All SAXS measurements were performed on a setup using an X-ray generator (rotating anode) from Rigaku. The flight path of the instrument was fully evacuated and the scattered radiation was detected by a 2D Bruker Hi-Star multiwire proportional chamber. Aluminum discs with a thickness of $1 \mathrm{~mm}$ and a central hole of $1 \mathrm{~mm}$ diameter, into which the powder-like samples were stuffed, served as sample holder. Measurements were taken at two different sample-detector distances in order to cover a broad range of scattering vectors $q$. The intensity scale of the two data sets was adjusted such that the data overlapped in the intermediate $q$-range. The first few data points (around $310^{-2} \AA^{-1}$ ) of the second data set (higher $q$ ) are affected by the beam stop and should not be evaluated. A background subtraction was not necessary as the scattering signal from the sample was much stronger than any background intensity.

Data analysis was based on the Debye-Bueche expression for a random two-phase system, $I(Q)=K /\left(1+a^{2} q^{2}\right)^{2}$. Here $K$ is a constant and $a$ is the correlation length, with $1 / a=$ 

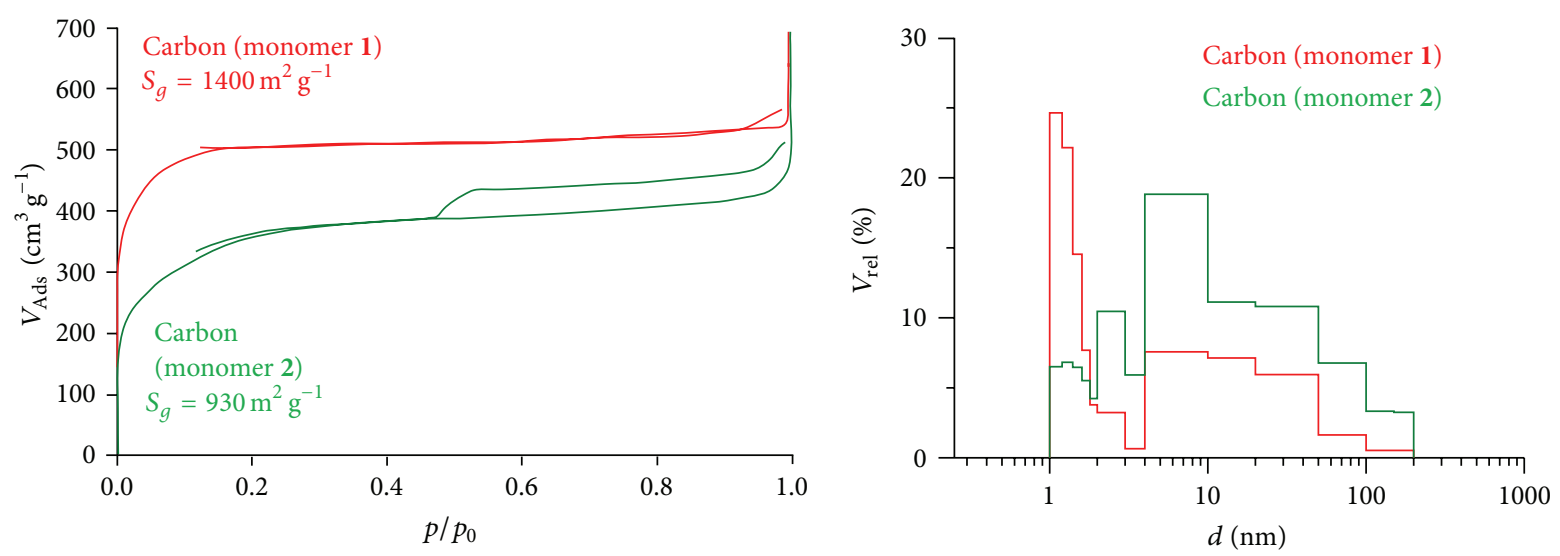

(a)
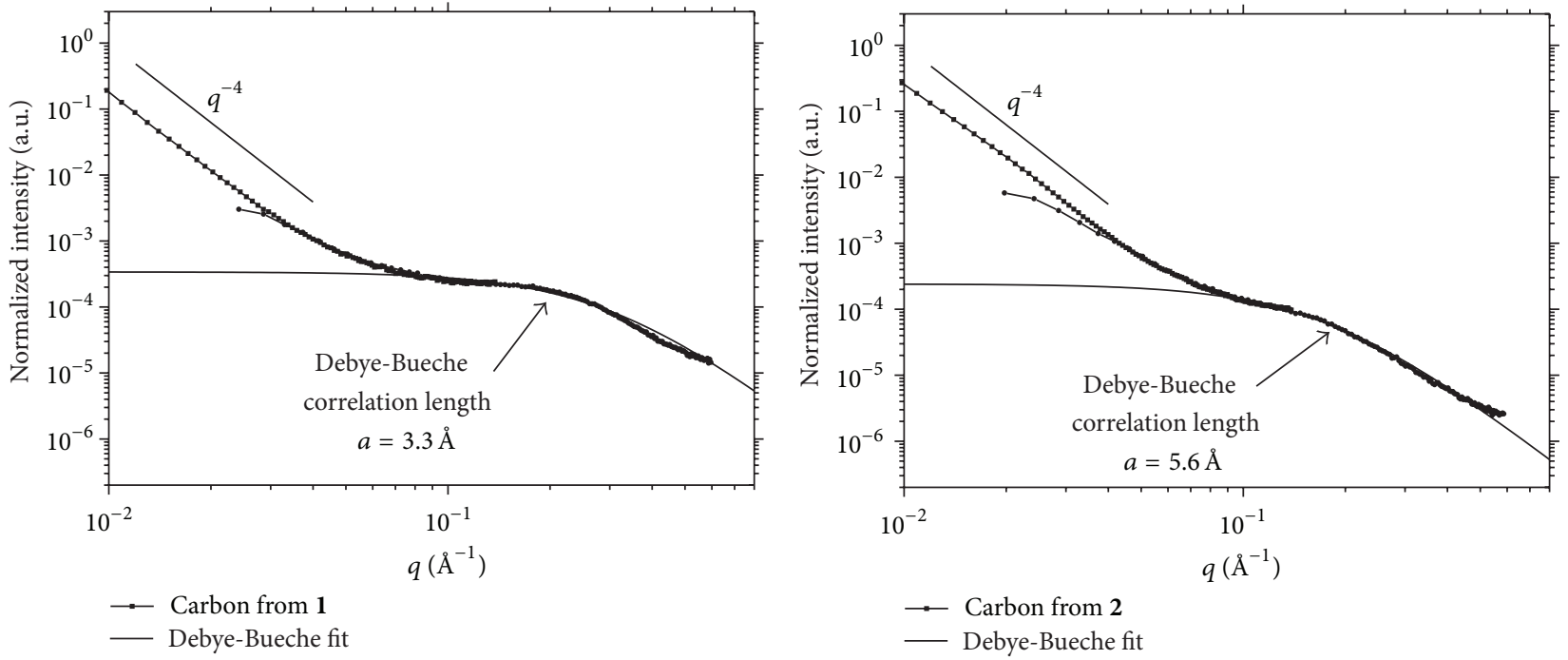

(b)

FIGURE 2: (a) Nitrogen-sorption-isotherms and pore-size distribution plots of carbon from template-free TP by acidic induction; (b) SAXS measurements of those carbon materials.

$1 / l_{1}+1 / l_{2}$, where $l_{1}$ and $l_{2}$ are the average chord length in phases 1 and 2, respectively; that is, the average is taken over the carbon phase as well as the pore phase [28, 29]. The correlation length gives therefore an average size of the two phases, weighted with the volume fractions.

\section{Results}

3.1. Verification of Carbon from Template-Free Procedure. The silicon based twin monomers $\mathbf{1}$ and $\mathbf{2}$ were polymerized after induction by an acid or thermal activation. Thereby, 1 reacts to a nanostructured $\mathrm{SiO}_{2} /$ phenolic resin and 2 to a nanostructured $\mathrm{SiO}_{2} /$ poly(furfuryl alcohol) hybrid material, as known from literature (see also Figure 1) $[16,22]$. Starting from those materials porous carbon was synthesized by carbonizing the polymer matrix and removing the $\mathrm{SiO}_{2}$ phase. The obtained carbons do not contain any residual $\mathrm{SiO}_{2}$; thermogravimetric analyses (TGA) show a complete mass loss, while a carbon content of $85 \mathrm{wt}-\%$ is measured by elementary analysis.
The Raman spectra of carbon derived from $\mathbf{1}$ and $\mathbf{2}$ are nearly congruent and contain characteristic D- and G-bands, which indicate amorphous carbon as well as X-ray powder diffraction did (see supplementary information, (Figures SI 1 and SI 2) in the Supplementary Material available online at http://dx.doi.org/10.1155/2013/872019).

Template-free acid induced polymerization of $\mathbf{1}$ leads to porous carbon, which contains mostly (according to literature: 72 vol-\%) micropores. In case of $\mathbf{2}$ mostly (mesopore content: 41 vol-\%) mesoporous carbon results from the same procedure (Figure 2).

Small angle X-ray scattering (SAXS) measurements support the results from gas sorption experiments. The scattering curves implicate pore texture on two length scales. The power law scattering at lower $q\left(I(q) \sim q^{-4}\right)$ is attributed to the larger mesopores and the external surfaces of the powder-like sample. The part of the data described by the Debye-Bueche expression reflects the small scale microporosity of the sample (higher $q$ ). The results shown in Figure S2 clearly indicate 


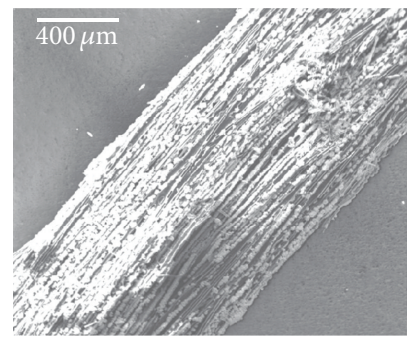

(a)

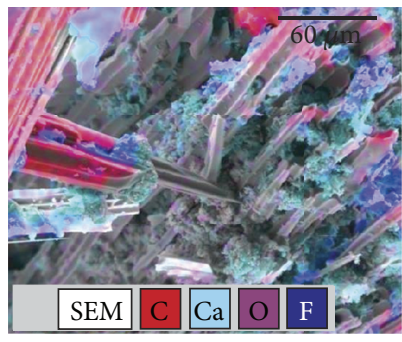

(b)

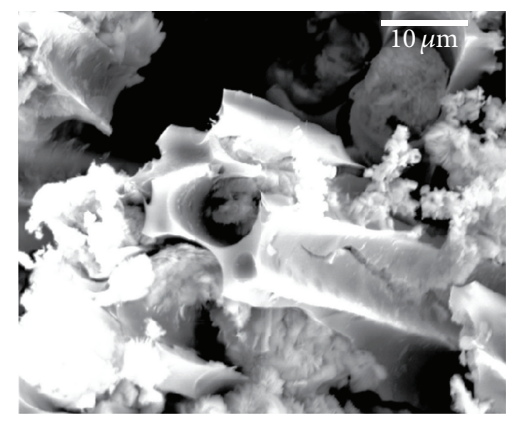

(c)

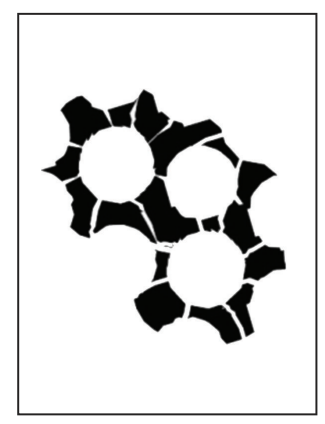

(d)

FIGURE 3: (a) Scanning electron microscopic (SEM) images of agglomerated carbon tubes; (b) energy dispersive X-ray (EDX) image of those tubes, (c) SEM image of a single tube and its surrounding, and (d) scheme of porous, agglomerated carbon tubes from glass fibre and $\mathbf{1}$

that the microporous structure in carbon from $\mathbf{1}$ has a smaller length scale (correlation length $a=3.3 \AA$ ) than porosity in carbon from $2(a=5.6 \AA)$. Thus, the results by nitrogensorption-isotherm and SAXS differ slightly, but both methods confirm consistently that the pore-size distributions depend on the starting twin monomer.

3.2. Glass Fibre Template. Pure $\mathrm{SiO}_{2}$-fibres are very rare and expensive. Thus, we chose commercially available glass fibres as a very cheap $\mathrm{SiO}_{2}$-rich but impure substrate. According to Figure 1(c) a functional $\mathrm{SiO}_{2} /$ polymer hybrid layer on the template surface should result in porous carbon tubes after removing the $\mathrm{SiO}_{2}$ phase.

The polymerization of $\mathbf{1}$ and $\mathbf{2}$ can be induced by acidic catalysis or by heating to $200^{\circ} \mathrm{C}$ under air. Both methods lead to a coated glass fibre (see supplementary information, Figure SI 3). Acidic catalysis can take place in solution or melt. Both monomers lead to very thin hybrid layers at the surface of the glass fibres, even by dip-coating into melt. The maximum carbon content of glass fibre, coated by acid induced polymerization, amounts to $15 \%$. Those thin layers are not stable enough to overcome the carbonization and etching procedure. They break down after carbonization and removing the $\mathrm{SiO}_{2}$ phase. It is not possible to increase the thickness of the hybrid layers, because inhomogeneous material results by acid activation of high concentrated monomer solution or a monomer melt.

Thus, it is necessary to induce the polymerization of the twin monomers thermally on the surface of the glass fibre. In this way a thick $\mathrm{SiO}_{2} /$ polymer hybrid layer can be generated on the surface of the template. The maximum carbon content of $33 \%$ was achieved by dip-coating into a monomer melt and thermal induction. The thick $\mathrm{SiO}_{2} /$ polymer hybrid shell leads to an $\mathrm{SiO}_{2} / \mathrm{C}$ layer after carbonization, which results in stable carbon tubes with a porous shell after HF treatment (Figure 3).

Since glass fibre templates consist of bundles and not of isolated fibres, the resulting carbon tubes are agglomerated. The inner diameter of those carbon tubes is about $8.4 \mu \mathrm{m}$
(Figure 3(c)), according to the template diameter (see supplementary information, Figure SI 3(a)). The outer diameter of the carbon tubes amounts to about $9 \mu \mathrm{m}$ (Figure 3(a)). Calcium fluoride is visible as white crystals in Figure 3(b) and verified by energy dispersive X-ray analysis (Figure 3(b)). Calcium fluoride formation occurs because industrial glass fibre is an impure $\mathrm{SiO}_{2}$ template. It contains also calcium oxide, aluminum oxide, and in traces magnesium oxide (see EDX-analysis, supplementary information, Figure SI 4). Due to the treatment with hydrofluoric acid, calcium oxide is converted to insoluble calcium fluoride. According to thermal gravimetric analysis, the whole material consists of $25 \mathrm{~m}-\%$ calcium fluoride. The synthesis of pure porous carbon bodies is suitable by the use of pure $\mathrm{SiO}_{2}$ templates (see next section).

There are no significant differences between the SEM images and Raman spectra of carbon tubes received either from 1 or from 2 (see supplementary information, Figures SI 1 and SI 5). In contrast to carbon derived from acidic induced twin monomers (Figure 2(a)) the nitrogen-sorptionisotherms are nearly congruent if the monomers were thermally induced (Figure 4(a)).

In general, the nitrogen-sorption-curves of carbon from thermally induced twin monomers are both type I isotherms, corresponding to microporous carbon [30]. Thus, the poresize distribution plot shows mostly micropores (carbon from 1: 73 vol- $\%$, carbon from 2: 75 vol-\%) and the specific surface areas of those carbons are $710 \mathrm{~m}^{2} \mathrm{~g}^{-1}$ (1) and $930 \mathrm{~m}^{2} \mathrm{~g}^{-1}$ (2). The specific surface area of carbon decreases dramatically by using glass fibre template $\left(510 \mathrm{~m}^{2} \mathrm{~g}^{-1}\right.$ and $\left.310 \mathrm{~m}^{2} \mathrm{~g}^{-1}\right)$ and the pore-size distribution (Figure 4(b)) shows mostly mesopores (carbon from 1: 50 vol-\%, carbon from 2: $46 \mathrm{vol}-$ $\%)$. However, the reason for different pore-size distribution lies in the occurrence of by-product and not in the type of induction. According to TGA measurements the carbon from polymerization of 1 on glass fibre consists of $25 \mathrm{~m}-\% \mathrm{CaF}_{2}$ and the product of using 2 consists of $75 \mathrm{~m}-\% \mathrm{CaF}_{2}$. Thus, the nitrogen-sorption experiments and the resulting poresize distributions are distorted. If $\mathrm{CaF}_{2}$ could be released from the mixture, the porous carbon should have a higher specific surface area and more micropores should be measured. To 

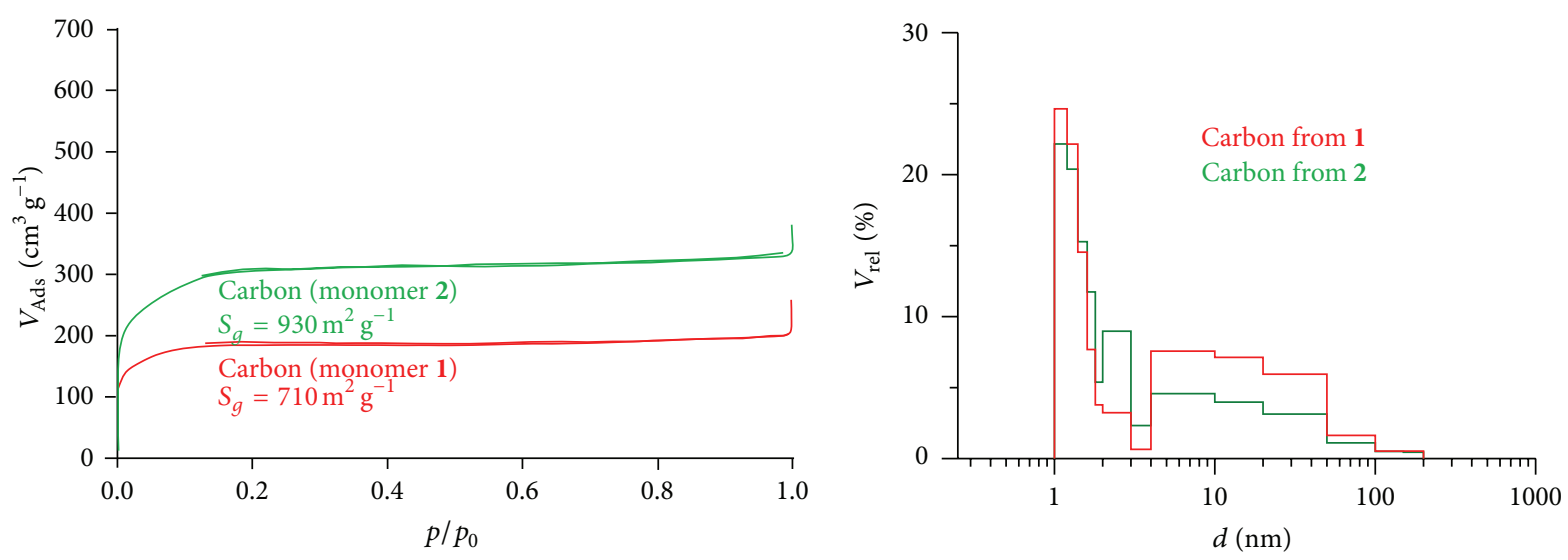

(a)
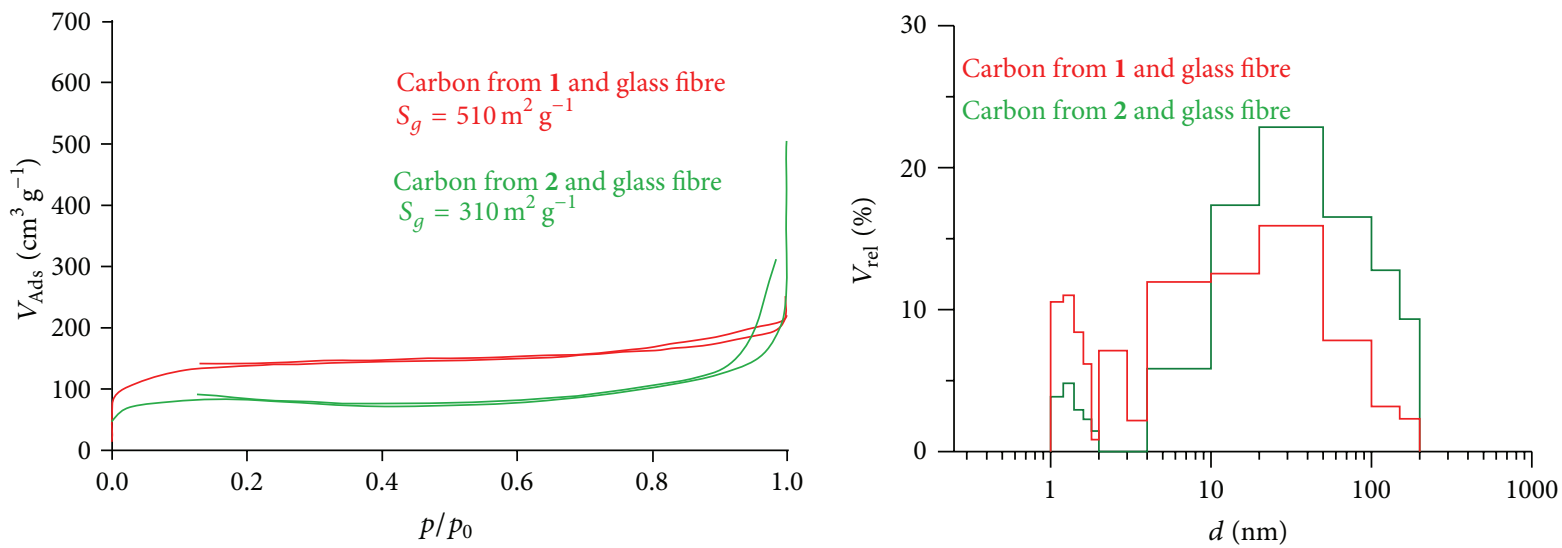

(b)

FIGURE 4: Nitrogen-sorption-isotherms and pore-size distribution plots (insets) of carbon from (a) from template-free TP by thermal induction AND (b) at glass fibre template by thermal induction.

avoid $\mathrm{CaF}_{2}$ as by-product a template should be used, which can be removed completely.

3.3. ORMOCER Templates. In order to overcome the drawbacks from standard impure $\mathrm{SiO}_{2}$-fibres we chose ORMOCERs as pure fibrous hollow $\mathrm{SiO}_{2}$ templates provided in small lots. Their use in the template assisted-TP of 1 will lead to pure porous carbon tubes without the formation of metal fluorides as by-product (Figure 5).

The tubular template is coated at the inner and the outer sides by thermally induced TP. After carbonization a functional $\mathrm{SiO}_{2} / \mathrm{C}$ layer remains at the inner and at the outer sides of the ORMOCER. Treatment with aqueous hydrofluoric acid completely removes the $\mathrm{SiO}_{2}$ of the ORMOCER, but the outer carbon layer breaks down (Figure 5(1b)), too. In this way porous solitary carbon tubes with a smooth surface were obtained (Figures 5(1a) and 5(1c)). The outer diameters of the carbon tubes are $100 \mu \mathrm{m}$ and $130 \mu \mathrm{m}$ and match exactly the inner diameters of ORMOCER 540 and ORMOCER 1051 templates. The inner diameters of the synthesized carbon tubes are about 70 and $90 \mu \mathrm{m}$.
The pore texture of the resulting carbon tubes is comparable with those of carbon tubes using glass fibre as template. The specific surface area is also reduced to $450 \mathrm{~m}^{2} \mathrm{~g}^{-1}$. Thus, not only the formation of $\mathrm{CaF}_{2}$ but also the shape of carbon tubes should be a reason for the lower specific surface areas.

As seen, dip-coating into a hot melt $\left(90^{\circ} \mathrm{C}\right)$ leads to porous carbon tubes (Figure 5), but it is not only possible to create the described species of carbon tubes by using ORMOCERs as template. The whole inner space of the ORMOCER tubes can be filled with monomer by dip-coating into an undercooled $\left(50^{\circ} \mathrm{C}\right)$ melt. The viscosity of the monomer melt increases with decreasing temperature and so the monomer melt has a honey-like viscosity at $50^{\circ} \mathrm{C}$ and does not flow out of the template. Thus, the completely filled inner template space results in porous carbon rods after polymerization, carbonization, and treatment with hydrofluoric acid.

The products from this procedure are porous carbon rods with diameters of $100 \mu \mathrm{m}$ and $130 \mu \mathrm{m}$ by using ORMOCER 540 (Figure 5(2a)) and ORMOCER 1051 (Figure 5(2b)) as templates. Larger porous carbon rods $(d=580 \mu \mathrm{m})$ can be produced by using glass capillary as cheap template (Figure $5(2 c)$ ). In comparison to the use of glass fibre templates 

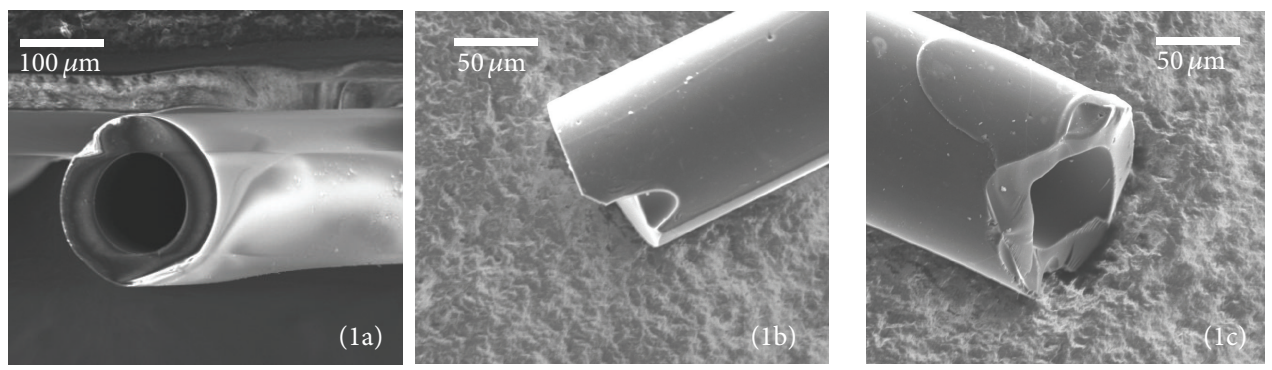

One template

$90^{\circ} \mathrm{C}$
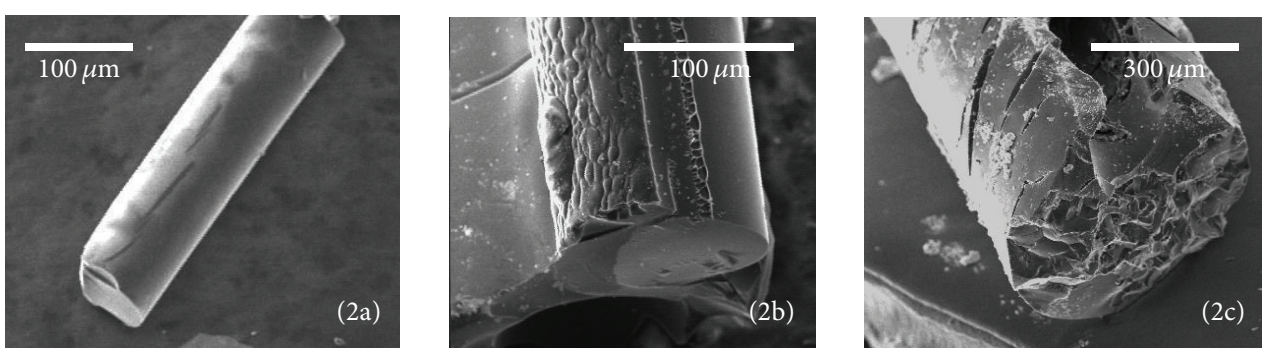

One template

$50^{\circ} \mathrm{C}$
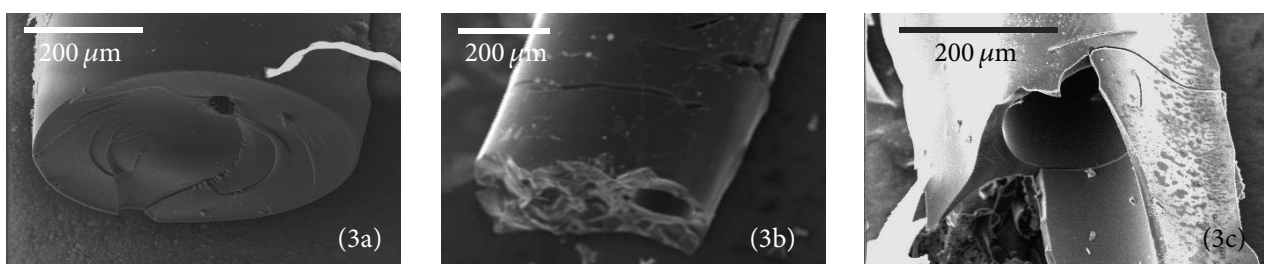

Two

templates

$50^{\circ} \mathrm{C}$

FIGURE 5: SEM images of (1a) pure $\mathrm{SiO}_{2}$-tube (ORMOCER 540); (1b) porous carbon tubes from ORMOCER 540 and 1; (1c) carbon tube from ORMOCER 1051 and 1. SEM images of carbon rods from 1 and (2a) ORMOCER 540, (2b) ORMOCER 1051, and (2c) a glass capillary. SEM images of porous carbon tubes, synthesized using a glass capillary as outer template and (3a) glass fibre, (3b) ORMOCER 540, and (3c) ORMOCER 1051 as inner template.

just a very small amount of calcium fluoride occurs as byproduct, because the carbon rods slide out of the glass capillary after carbonization.

3.4. Combination of Templates. It is possible to combine a glass capillary as outer template with ORMOCERs or glass fibre as inner templates. In this procedure the smaller template has been put into the glass capillary, and both templates were dipped into the monomer melt and heated up to induce the polymerization. After carbonization and treating with aqueous hydrofluoric acid, porous carbon tubes with a defined outer diameter and inner diameter result (Figures 5(3a), 5(3b), and 5(3c)).

In case of using glass fibres as inner template a small channel of about $40 \mu \mathrm{m}$ is visible in the $580 \mu \mathrm{m}$ thick porous carbon tube (Figure 5(3a)). The channel size is increasing by using ORMOCER 540 (Figure 5(3b)) and ORMOCER 1051 (Figure 5(3c)) up to $160 \mu \mathrm{m}$ and $220 \mu \mathrm{m}$.

\section{Summary}

Porous cylindrical carbon bodies with a tailored shape were synthesized by template-assisted TP. ORMOCERs, glass fibres, and glass capillaries with various inner and outer diameters were coated by surface TP of two different twin monomers at their surfaces. Porous carbon tubes of well tailored morphology result after carbonization and release of $\mathrm{SiO}_{2}$. The route of template-assisted TP allows the synthesis of porous carbon of any shape in only one procedure. The outer diameter of carbon rods or tubes can be controlled by an outer template, like a glass tube, and the inner diameter by an inner template like glass fibre or ORMOCERs.

This work points out the high potential of the templateassisted TP, which could be used to create hollow carbon bodies of almost any shape or size, according to desired properties for application. Currently, more monomers and templates are under investigation.

\section{Conflict of Interests}

The paper describes original research. The authors used several templates to produce nanostructure carbon. ORMOCER is one of those templates. The research is not influenced by a secondary interest, such as financial gain.

\section{Acknowledgments}

The authors gratefully acknowledge the Deutsche Forschungsgemeinschaft for financial support DFG (Project: Sp 392/31-1) and Cordus $\mathrm{GmbH}$ for providing glass fibre. The substance classis called ORMOCER was provided by Fraunhofer-Institut für Silicatforschung ISC in Würzburg to 
support the research project. Thus, the authors thank Dr. Ladislav Kido and Dr. Thomas Ballweg for providing this template without any financial interests.

\section{References}

[1] B. Hu, K. Wang, L. Wu, S. H. Yu, M. Antonietti, and M. M. Titirici, "Engineering carbon materials from the hydrothermal carbonization process of biomass," Advanced Materials, vol. 22, no. 7, pp. 813-828, 2010.

[2] F. Su, X. S. Zhao, Y. Wang, L. Wang, and J. Y. Lee, "Hollow carbon spheres with a controllable shell structure," Journal of Materials Chemistry, vol. 16, no. 45, pp. 4413-4419, 2006.

[3] T. N. Hoheisel, S. Schrettl, R. Szilluweit, and H. Frauenrath, "Nanostructured carbonaceous materials from molecular precursors," Angewandte Chemie, vol. 49, no. 37, pp. 6496-6515, 2010.

[4] S. H. Joo, S. J. Choi, I. Oh et al., "Ordered nanoporous arrays of carbon supporting high dispersions of platinum nanoparticles," Nature, vol. 412, pp. 169-172, 2001.

[5] G. S. Chai, S. B. Yoon, J. H. Kim, and J. S. Yu, "Spherical carbon capsules with hollow macroporous core and mesoporous shell structures as a highly efficient catalyst support in the direct methanol fuel cell," Chemical Communications, no. 23, pp. 2766-2767, 2004.

[6] S. Ikeda, S. Ishino, T. Harada et al., "Ligand-free platinum nanoparticles encapsulated in a hollow porous carbon shell as a highly active heterogeneous hydrogenation catalyst," Angewandte Chemie - International Edition, vol. 45, no. 42, pp. 70637066, 2006.

[7] K. T. Lee, Y. S. Jung, and S. M. Oh, "Synthesis of tin-encapsulated spherical hollow carbon for anode material in lithium secondary batteries," Journal of the American Chemical Society, vol. 125, no. 19, pp. 5652-5653, 2003.

[8] B. Zhang, X. Qin, G. R. Li, and X. P. Gao, "Enhancement of long stability of sulfur cathode by encapsulating sulfur into micropores of carbon spheres," Energy and Environmental Science, vol. 3, no. 10, pp. 1531-1537, 2010.

[9] H. Tamai, T. Sumi, and H. Yasuda, "Preparation and characteristics of fine hollow carbon particles," Journal of Colloid and Interface Science, vol. 177, no. 2, pp. 325-328, 1996.

[10] S. Han, S. Kim, H. Lim et al., "New nanoporous carbon materials with high adsorption capacity and rapid adsorption kinetics for removing humic acids," Microporous and Mesoporous Materials, vol. 58, no. 2, pp. 131-135, 2003.

[11] G. Shen, Y. Bando, C. Zhi, and D. Golberg, "Tubular carbon nano-/microstructures synthesized from graphite powders by an in situ template process," Journal of Physical Chemistry B, vol. 110, no. 22, pp. 10714-10719, 2006.

[12] L. Gherghel, C. Kübel, G. N. Lieser, H. J. Räder, and K. Müllen, "Pyrolysis in the mesophase: a chemist's approach toward preparing carbon nano- and microparticles," Journal of the American Chemical Society, vol. 124, no. 44, pp. 13130-13138, 2002.

[13] Y. Xiong, Y. Xie, Z. Li, C. Wu, and R. Zhang, "A novel approach to carbon hollow spheres and vessels from $\mathrm{CCl}_{4}$ at low temperatures," Chemical Communications, vol. 9, no. 7, pp. 904905, 2003.

[14] R. L. Vander Wal, "Flame synthesis of Ni-catalyzed nanofibers," Carbon, vol. 40, no. 12, pp. 2101-2107, 2002.
[15] S. Kubo, I. Tan, R. J. White, M. Antonietti, and M. M. Titirici, "Template synthesis of carbonaceous tubular nanostructures with tunable surface properties," Chemistry of Materials, vol. 22, no. 24, pp. 6590-6597, 2010.

[16] S. Spange, P. Kempe, A. Seifert et al., "Nanocomposites with structure domains of 0.5 to $3 \mathrm{~nm}$ by polymerization of silicon spiro compounds," Angewandte Chemie-International Edition, vol. 48, no. 44, pp. 8254-8258, 2009.

[17] L. Matéjka, K. Dusek, J. Plestil, J. Kriz, and L. Ldnicky, "Formation and structure of the epoxy-silica hybrids," Polymer, vol. 40, no. 1, pp. 171-181, 1998.

[18] Y. Wei, D. Jin, C. Yang, and G. Wei, "A fast convenient method to prepare hybrid sol-gel materials with low volume-shrinkages," Journal of Sol-Gel Science and Technology, vol. 7, no. 3, pp. 191201, 1996.

[19] M. E. Ellsworth and B. M. Novak, "Mutually interpenetrating inorganic-organic networks new routes into nonshrinking solgel composite materials," Journal of the American Chemical Society, vol. 113, no. 7, pp. 2756-2758, 1991.

[20] A. Chemtob, D. L. Versace, C. Belon, C. Croutxé-Barghorn, and S. Rigolet, "Concomitant organic-inorganic UV-curing catalyzed by photoacids," Macromolecules, vol. 41, no. 20, pp. 7390-7398, 2008.

[21] M. Uygun, W. D. Cook, C. Moorhoff et al., "Photopolymerization kinetics and dynamic mechanical properties of silanes hydrolyzed without evolution of byproducts. Tetrakis[(methacryloyloxy)ethoxy] silane-diethylene glycol dimethacrylate," Macromolecules, vol. 44, no. 7, pp. 1792-1800, 2011.

[22] S. Grund, P. Kempe, G. Baumann, A. Seifert, and S. Spange, "Nanocomposites prepared by twin polymerization of a singlesource monomer," Angewandte Chemie-International Edition, vol. 46, no. 4, pp. 628-632, 2007.

[23] A. Mehner, T. Rüffer, H. Lang, A. Pohlers, W. Hoyer, and S. Spange, "Synthesis of nanosized $\mathrm{TiO}_{2}$ by cationic polymerization of ( $\mu_{4}$-oxido)-hexakis( $\mu$-furfuryloxo)-octakis(furfuryloxo)-tetra-titanium," Advanced Materials, vol. 20, no. 21, pp. 4113-4117, 2008.

[24] S. Spange and S. Grund, "Nanostructured organic-inorganic composite materials by twin polymerization of hybrid monomers," Advanced Materials, vol. 21, no. 20, pp. 2111-2116, 2009.

[25] F. Böttger-Hiller, R. Lungwitz, A. Seifert et al., "Nanoscale tungsten trioxide synthesized by in situ twin polymerization," Angewandte Chemie-International Edition, vol. 48, no. 47, pp. 8878-8881, 2009.

[26] G. Horvath and K. Kawazoe, "Method for calculation of effective pore size distribution in molecular sieve carbon," Journal of Chemical Engineering of Japan, vol. 16, no. 6, pp. 470-475, 1983.

[27] F. Böttger-Hiller, P. Kempe, G. Cox et al., "Twin Polymerization at spherical hard-templates: an approach to size adjustable carbon hollow spheres with micro- or mesoporous shells," Angewandte Chemie - International Edition, vol. 52, no. 23, pp. 6088-6091, 2013.

[28] P. Debye and A. M. Bueche, "Scattering by an inhomogeneous solid," Journal of Applied Physics, vol. 20, no. 6, pp. 518-525, 1949.

[29] O. Glatter and O. Kratky, Small Angle X-Ray Scattering, Academic Press, London, UK, 1982.

[30] J. Seifert and G. Emig, "Mikrostrukturuntersuchungen an porösen Feststoffen durch Physisorptionsmessungen," Chemie Ingenieur Technik, vol. 59, no. 6, pp. 475-484, 1987. 

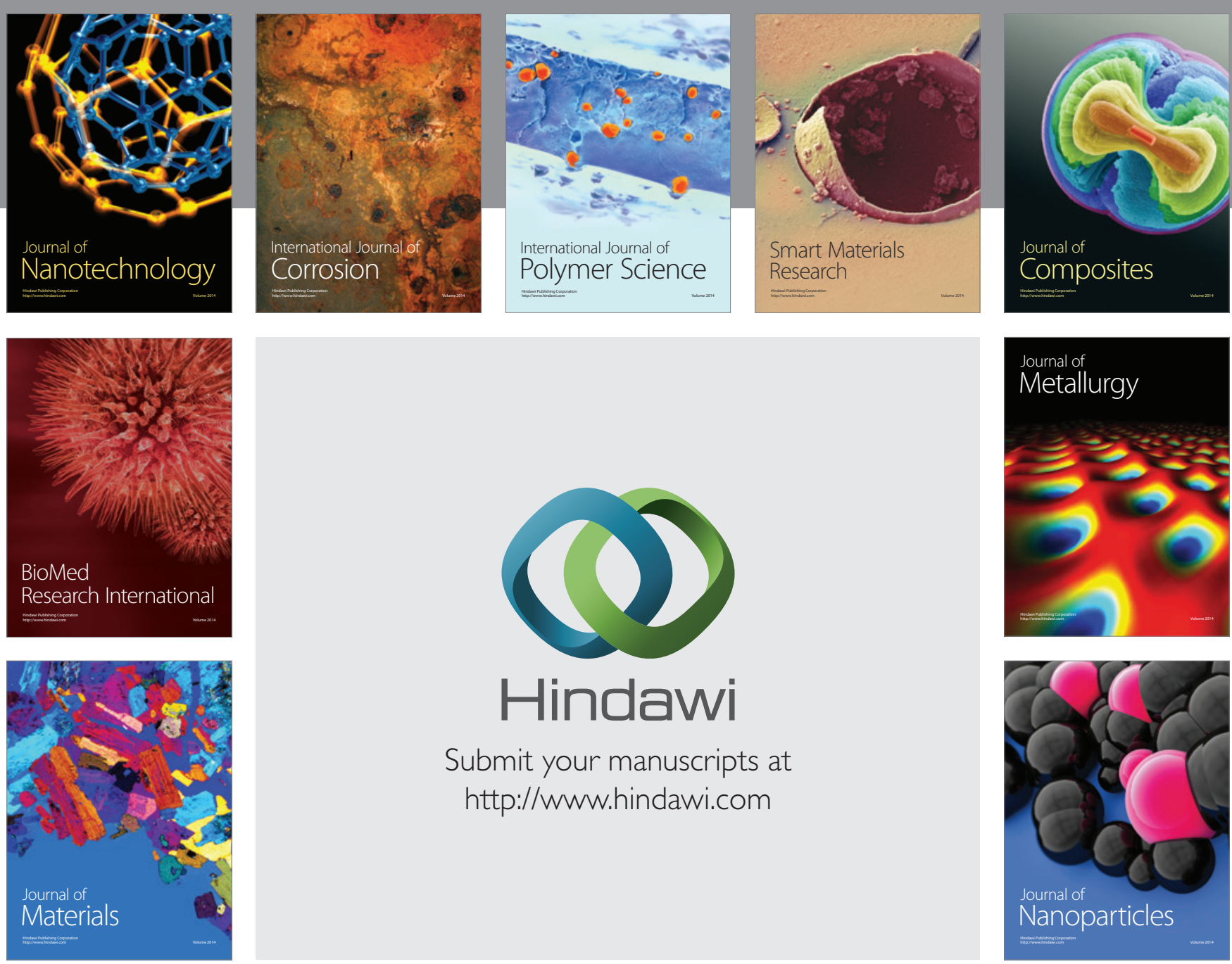

Submit your manuscripts at http://www.hindawi.com
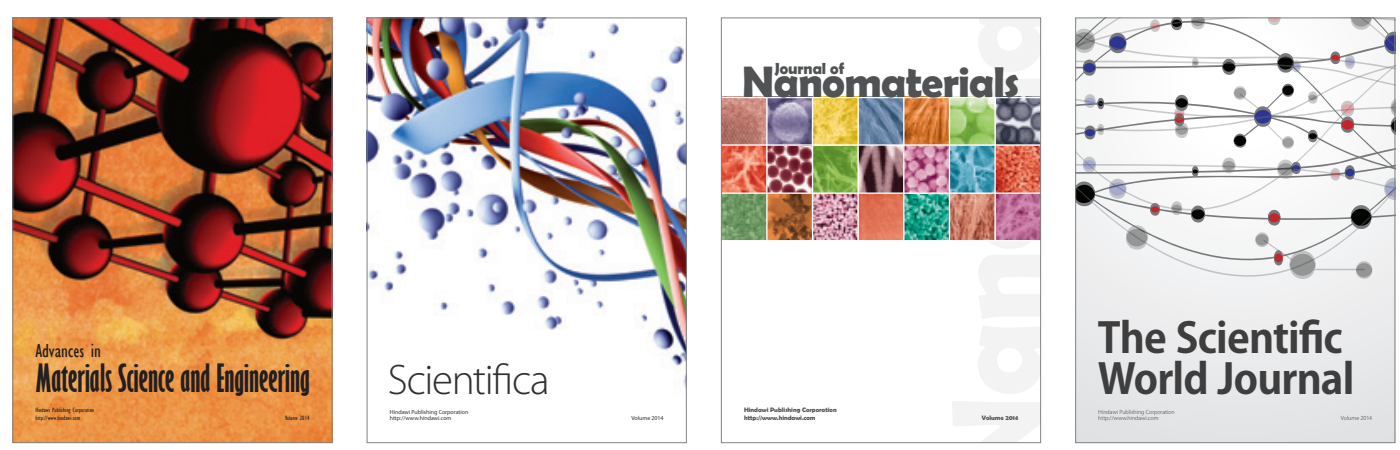

\section{The Scientific World Journal}
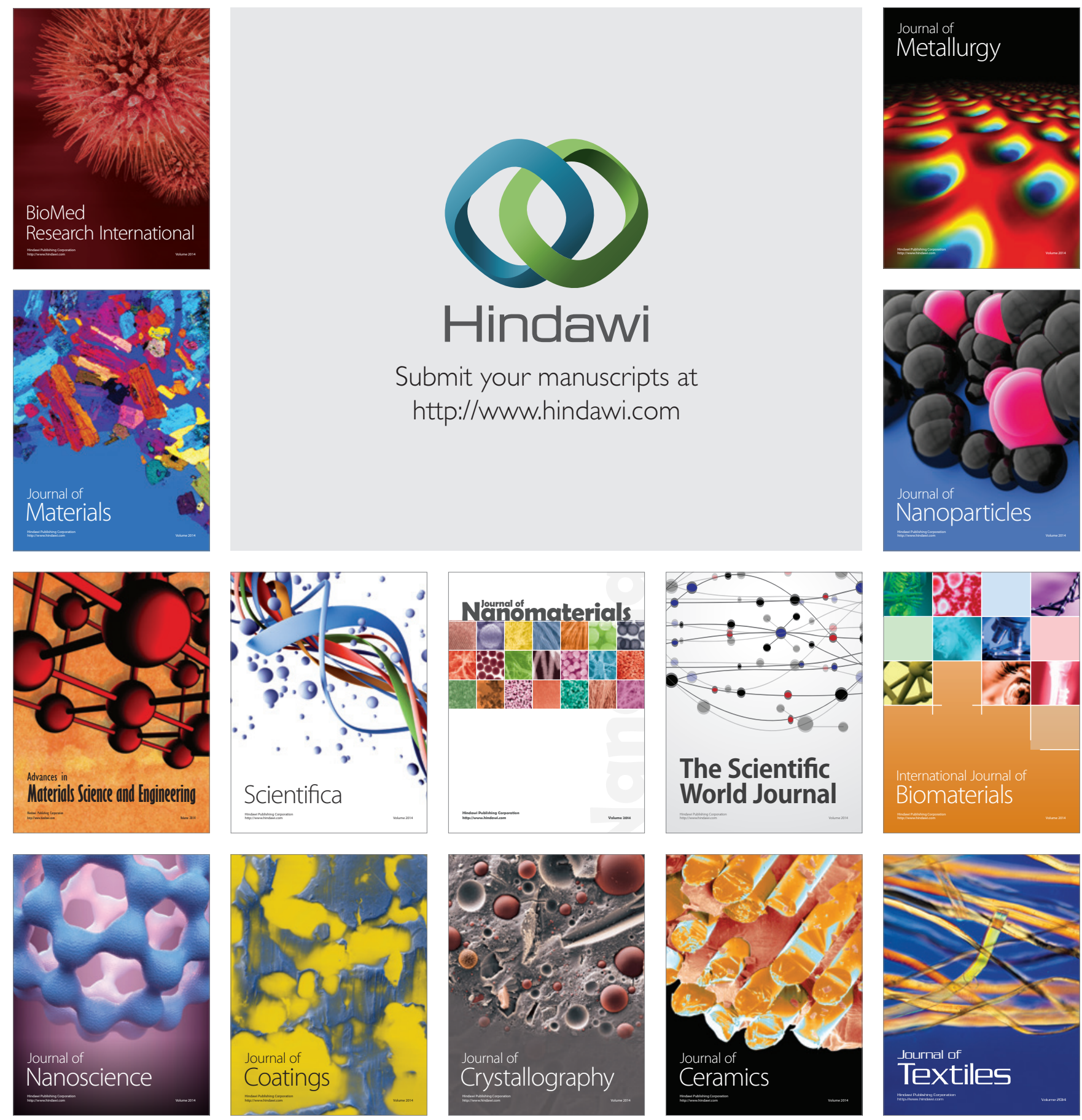